\title{
Attitudes to usage vs. actual language use: The case of literally in American English
}

\author{
VIKTORIJA KOSTADINOVA
}

\author{
American English speakers know how and why they use \\ literally
}

\section{Introduction}

From a descriptive point of view, literally is seen as 'a case of semantic change in progress' (Israel, 2002: 424), exemplified through the shift from uses such as This word literally means 'water' to This book literally blew my mind. This process of change has been noticed and commented on by language commentators and usage guide writers. In other words, apart from being a case of change in progress, literally is also a usage problem. Usage problems are 'features of divided usage', or 'instances of usage that have attracted sociolinguistic controversy' (Tieken-Boon van Ostade, 2015: 57; cf. Kostadinova, 2018). The case of the word literally, then, lends itself to an investigation of the relationship between prescriptive approaches to language use typically found in usage guides, and processes of language variation and change, as I will do in this paper. As a crucial aspect to this discussion, I will also address some of the attitudes speakers hold towards the newer uses of literally, as attitudes of speakers can help us better understand why prescriptivism may or may not influence language variation and change. In what follows, I will first discuss the variant uses of literally found in present-day English, and then consider findings on three perspectives on the variation in the use of literally, viz. the 'usage guide' perspective, the 'actual use' perspective and the 'speakers' attitudes' perspective.

\section{Variation and change in the use of literally}

In addition to its primary use to mean 'in a literal sense' and as 'word for word' (OED, s.v. literally), literally is used as a stance adverbial (Biber et al., 1999: 767), or a metalinguistic adjunct (Huddleston \& Pullum, 2002: 775; see also Quirk et al., 1985: 618-19) the function of which is to clarify how a word or phrase is to be understood. Speakers can use literally as a stance adverbial 'to convey their judgements and attitudes, to claim the factual nature of what they are saying, and to mark exactly how they mean their utterances to be understood' (Biber et al., 1999: 766-7). One such example, taken from Biber et al. (1999: 767) is 'Put one in, put the pill in, put another one in. Yeah, literally!'. This subjective, attitudinal component in the use of literally is what accounts for the variation observed in its use in present-day English (Powell, 1992; Israel, 2002).

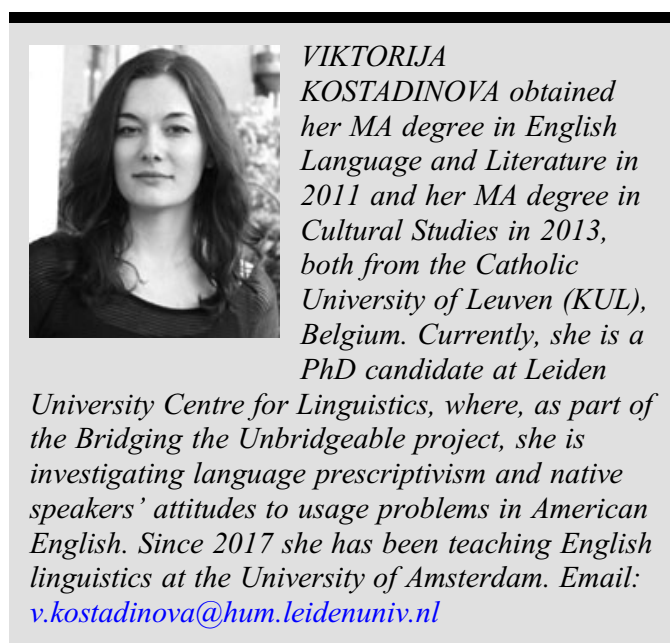


In one of the earliest detailed analyses of the uses of literally, Powell examines 'five categories of contemporary use' (1992: 337), four of which have developed from the primary use. Subsequent discussions of literally offer similar classifications of its uses (cf. Israel, 2002; Nerlich \& Chamizo Domínguez, 2003; Calhoun, 2015); for reasons of space I focus here on Powell's classification. The five uses Powell identifies are: 1) the 'folk definitional' use, to refer to what something means, how something is to be understood, interpreted or translated, or as an equivalent of technically; 2) 'with lexemes which denote extreme cases', including number expressions of exceptional quantity; 3) 'with dual readings', where literally modifies a conventionally idiomatic or figurative expression, signalling that the expression should be interpreted literally; 4) 'with formulary expressions'; and 5) 'with nonresonant, nonliteral expressions'. These uses are exemplified in $(1)-(5)$, respectively (emphasis added in bold). ${ }^{1}$ Historically, the first use is the oldest, and was found predominantly in contexts related to the interpretation of the Bible and other sacred texts (Israel, 2002; Nerlich \& Chamizo Domínguez, 2003), where the difference between a literal and a figurative reading had important moral implications (Powell, 1992). The newer uses of literally, including those with nonliteral expressions, seem to have developed at a later stage (cf. Israel, 2002: 424-26). This is also supported by the $O E D$ entry on literally, in which uses similar to those of the primary use of literally identified by Powell were first attested earlier than the use of literally with metaphorical or hyperbolical expressions, whose earliest attestation comes from 1769.

1. The Gaelic word for whiskey, Usquebaugh, literally means 'water of life.' (1990, academic, COCA) $)^{2}$

2. I was seated next to Al Giddings, an underwater photographer who once literally pulled another photographer from the jaws of a great white. (2006, magazine, COCA)

3. DeLauro is not alone, says Dr. Judy Kuriansky, who literally wrote the book on the subject, called 'How to Love a Nice Guy.' (1991, newspaper, COCA)

4. Obsessing over healthy food is a decades-long pastime in L.A. Local grocery stores such as Erewhon and Whole Foods Market and restaurants such as Real Food Daily literally feed the frenzy, making the city a breeding ground for people attracted to a 'pure' lifestyle. (2001, magazine, COCA)
5. I don't even know who these people are, and suddenly they have literally exploded into the American consciousness. (2009, spoken, COCA)

In the first use, illustrated in (1), literally signals that the expression it modifies should be taken in the strictest sense of the word. Even though in this use the compositional (i.e. literal) meaning of the lexeme literally is the strongest, a crucial component is the attitudinal dimension, i.e. the speaker's attitude to 'the fit of word-to-word or word-to-world' (Powell, 1992: 341). It is this attitudinal component that accounts for the development of the newer uses of literally. The second use of literally distinguished by Powell, illustrated in (2), is with expressions denoting extreme cases, where 'the presence of literally is intended to force a non-hyperbolical - that is, a literal - meaning', simultaneously increasing the 'rhetorical emphasis on the extreme case' (Powell, 1992: 342). In example (2), the extreme case is the photographer being pulled from the jaws of a great white shark. In other words, according to Israel (2002: 425), insisting that what one means is what one is saying 'is to acknowledge that it might not sound believable, and so, to emphasize that it is remarkable'. The third use of literally, exemplified in (3), is found in cases where it forces a dual reading of an expression. Here, the expression modified by literally, wrote the book on the subject, is an idiomatic one which conventionally has a nonliteral reading (the $O E D$ defines to write the book (on) as 'to be the original expert or authority (on something); to set the standard' (OED, s.v. book)). In this case, literally is used to signal to the interlocutor that an expression that is conventionally interpreted figuratively should in this case be interpreted literally (Goatly, 1997: 174). The fourth use identified by Powell is distinguished by an element of creativity and semantic innovation. In this use, 'literally serves both truth conditional and aesthetic functions' (Powell, 1992: 344). According to Israel (2002: 426), literally is used 'to draw attention to an apt or clever choice of words' or to emphasise 'the peculiar suitability of a given choice of words for the described situation'. An example is found in (4), where the speaker uses literally to modify the expression feed the frenzy to suggest that the supermarkets cater for nutrition concerns by providing appropriate products. The speaker is not suggesting that frenzy is being literally fed, but is making an aesthetic or creative point, by using the expression feed the frenzy to refer to nutrition. Finally, the fifth use of literally involves 
nonliteral expressions which are unlikely to be literally true. When used with metaphorical or hyperbolic expressions in this case, 'the function of literally is to encode the speaker's aesthetic judgment that the message, as expressed, is not merely warranted by its capacity to satisfy conditions of applicability but is especially tellable' (Powell, 1992: 345) or 'to tell the reader that the hyperbolical mode itself is justified by the conditions it applies to and that the lexeme that encodes it is a particularly apt one' (1992: 346). This use is exemplified by (5), where the word exploded is used figuratively. According to Powell (1992: 337), these are the most interesting cases, adding that 'contrary to what one might expect, this use is neither odd nor paradoxical; rather, it illustrates that the lexeme exhibits great continuity of function in both literal and nonliteral environments'.

\section{Data and methodology}

The approach adopted here is largely based on that taken in historical-sociolinguistic studies investigating the effects of prescriptivism on language change, referred to as precept vs. practice (Auer \& González-Díaz, 2005). The method consists of comparing the treatment of usage features in normative grammars, i.e. precept, to patterns of use observed in actual language use, i.e. practice (e.g. Dekeyser, 1975; Auer \& González-Díaz, 2005). Similarly, in studies of the influence of usage guides on actual usage (e.g. Albakry, 2007; Peters, 2014; Ebner, 2017; Kostadinova, forthcoming), usage guides pronouncements are contrasted with patterns of actual use of selected language variants in corpora. In the same vein, this paper uses precept data from American usage guides, and corpus data from the Corpus of Historical American English (COHA; Davies, 2010-) and the Corpus of Contemporary American English (COCA; Davies, 2008-) in order to compare the treatment of literally as a usage problem with its actual use. For evidence of speakers' attitudes towards the variation in the use of literally, I will draw on data from interviews with native speakers of American English I conducted in 2014. In what follows, I will discuss each of these datasets in more detail.

\subsection{Precept data}

The precept data comes from a collection of 70 American usage guides, published between 1847, the year of the earliest recorded instance of an American usage guide (Connors, 1983; TiekenBoon van Ostade, 2015), and 2014. The Hyper
Usage Guide of English database (HUGE; Straaijer, 2014) was the main source of usage guide entries, supplemented with guides obtained through additional searches (for details of the selection procedure and the usage guides analysed, see Kostadinova, 2018 and Kostadinova, forthcoming). 32 entries on literally were identified in these usage guides and subsequently analysed; the results of this analysis will be discussed in Section 4. The entries' contents were first classified into three mutually exclusive categories, viz. ACCEPTABLE, RESTRICTED and UNACCEPTABLE, following an approach taken in studies of usage guides (Creswell, 1975; Peters \& Young, 1997; Albakry, 2007; Peters, 2014; Ebner, 2017; Kostadinova, forthcoming) and of normative grammars (e.g. Dekeyser, 1975). Entries given the label UNACCEPTABLE express a categorical disapproval of any uses of literally other than in its literal meaning, as in (6). RESTRICTED entries are those in which either no explicit approval is expressed, or intensifying and nonliteral uses of literally are accepted in certain contexts only. An example of a RESTRICTED entry is found in (7). ACCEPTABLE entries are those in which the variation in the use of literally is straightforwardly accepted. Such entries were not identified in the analysis.

6. Literally for Figuratively. 'The stream was literally alive with fish.' 'His eloquence literally swept the audience from its feet.' It is bad enough to exaggerate, but to affirm the truth of the exaggeration is intolerable. (Bierce, 1909: 42)

7. Literally means 'actually, without deviating from the facts,' but it is so often used to support metaphors that its literal meaning may be reversed. In statements like the following, literally means 'figuratively' and literal means 'figurative' [ ... ] Literal-minded readers find such locutions absurd. (Ebbitt \& Ebbitt, [1939] 1978: 547-8)

This kind of analysis, in which each entry is classified into one of three mutually exclusive categories, helps to reveal general patterns of precept, as well as changes in precept over time. In order to find out what is actually said about literally in the usage guide entries analysed, the analysis of treatment was supplemented with a more finegrained analysis of the attitudes expressed towards the nonliteral use of literally, i.e. particular words or phrases in the entries which express an opinion or an evaluation of the nonliteral use of literally. I distinguish two categories: positive attitude expressions and negative attitude expressions (cf. 
Kostadinova, forthcoming for further details on this kind of analysis). Illustrative cases of positive and negative attitudes in the usage guides are given in (8) and (9), respectively.

8. [T] he hyperbolic use of literally is neither a misuse not a mistake for some other word [ ... ] (Gilman, 1989: 607)

9. Literally here is excess baggage, and the sentence is more forceful without it. (Copperud, 1980: 231)

\subsection{Corpus data}

The data on the patterns of actual use consists of occurrences of literally extracted from the full-text data of COHA and COCA. Because of the necessity for a manual disambiguation of the occurrences of literally, a representative sample was used for the analysis, obtained by selecting every fifth occurrence of literally from the total number of occurrences; details are given in Table 1.

The occurrences in the samples were then disambiguated on the basis of a tripartite classification of uses, adapted from the five uses identified by Powell, discussed in Section 2 above; the three categories I distinguish are BASIC USE, DUAL USE and NONLITERAL USE. BASIC USE refers to the primary uses of literally, exemplified in (1) above. Dual USE comprises three of the uses of literally identified by Powell (1992: 341-4), which I discussed above, viz. literally with expressions denoting 'extreme cases' (example [2]), literally in 'dual readings' (example [3]) and literally as 'semantic innovator' (example [4]). These are all cases in which literally is used to force a literal reading of an expression which is otherwise likely to be interpreted nonliterally. Leaving literally out in all these cases would affect the interpretation of the expression it modifies. In the context of my analysis, I refer to all three of these as DUAL USE, because in all of them both the conventional and the literal meanings are operative. The third category, NONLITERAL USE, is the use of literally with nonliteral expressions, exemplified in (5). These uses violate the basic, propositional meaning of literally, thus maximising its nonliteral, pragmatic force. The decision to conflate three of the uses identified by Powell under the category DUAL was made primarily because I am interested here specifically in the occurrence of the primary and the nonliteral uses of literally, which is important for the question of the relationship between usage guides treatment and actual use (but see Kostadinova, in preparation).

\subsection{Interview data}

The interview data comes from conversations with 70 native speakers of American English, who participated in a study of attitudes to usage as part of a survey conducted in Los Angeles in 2014. These post-survey interviews were meant to give participants a chance to discuss the questions in the survey more extensively. Sentences with nonliteral literally were included in the survey, so literally naturally came up as a topic of discussion. The participants came from different ethnic and professional backgrounds; the majority were between 19 and 40 years of age. The selection of participants was done using the friend-of-a-friend method, which resulted in a convenience sample. This means that it is difficult to make any claims of representativeness. As a result, I will not focus on making quantitative statements, and will only look at the kinds of attitudes the participants expressed. Since the interviews were semistructured, the use of literally was commented on explicitly by 53 participants; the discussion here is based on those comments. The perspective I will be concerned with here is the acceptance of newer uses of literally by the speakers.

\section{Literally in the usage guides}

From the point of view of its discussion in the usage guides, literally is a typical $20^{\text {th }}$-century usage problem, as shown in Figure 1.

The classification of these entries into the three mutually exclusive categories ACCEPTABLE,

Table 1: Corpus data for literally retrieved from COHA and COCA

\begin{tabular}{|lccc|}
\hline Corpus & Period & Number of occurrences & Sample size \\
\hline COHA & $1810-1989$ & 5,778 & 1,155 \\
\hline COCA & $1990-2012$ & 14,519 & 2,904 \\
\hline Total & & $\mathbf{2 0 , 2 9 7}$ & $\mathbf{4 , 0 5 9}$ \\
\hline
\end{tabular}




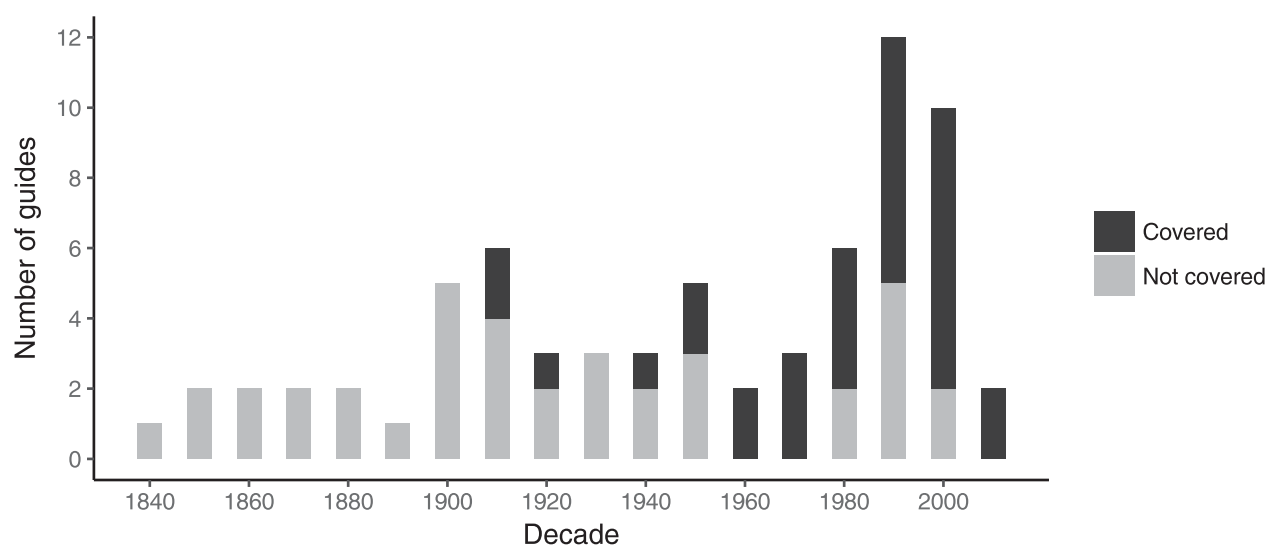

Figure 1. Number of usage guides which cover literally from the total number of usage guides analysed per decade

RESTRICTED and UNACCEPTABLE established in Section 3.1 reveals that this feature is largely considered unacceptable. Of the 32 entries, 24 were classified as UNACCEPTABLE, meaning that the authors accept only literal uses of literally. The remaining 8 entries were classified as RESTRICTED, i.e. the authors either accept the different variants of literally, including the nonliteral use, in certain less formal contexts, or they are vague in their treatment, and do not express any attitudes to the acceptability of the feature overtly. In terms of changes in treatment, then, the pattern in Figure 2 shows that there has been no change in how literally is perceived over the years from the point of view of correct usage. The presence of a small number of RESTRICTED entries is more likely to be an effect of variation within the genre of usage guides than an indicator of a change in precept, as less prescriptive usage guides tend to acknowledge patterns of language variation and change without overt negative judgements.

The number of positive and negative attitudes in the entries shows a striking contrast, with negative attitudes being far more common than positive ones. This is hardly surprising, given the overall treatment of literally. Positive attitudes are rare, and occur only in two guides, which, for instance, acknowledge that literally is 'neither a misuse nor a mistake' (Gilman, 1989: 607), but a logical development within a process of language change. Furthermore, instead of deriding those who use literally in not strictly literal uses, one entry (Peters, 2004: 326) recognises the subjective and expressive nature of this use. Despite this more balanced account, these two guides still advise language users to exercise care in using literally for emphasis. Negative attitudes are far more prevalent. From this perspective, literally is considered a 'misuse' (Copperud, 1980: 231; Johnson, 1991: 365), which is 'intolerable' (Bierce, 1909: 42) or 'superfluous' (Pinker, 2014: 276). Its use is associated with confusion about its meaning (O'Conner, 1996: 85), or absurdity of expression (Ebbitt \& Ebbitt, [1939] 1978: 548). The claim that this use of literally prevents the reader from understanding what is meant (Clark, 2010: 148) and may evoke 'ludicrous' images as a result (Stilman, 1997: 39; Pinker, 2014: 276) is also found in the entries. As an intensifier, literally is seen as 'excess baggage' (Copperud, 1980: 231) that 'should be avoided' (Evans \& Evans, 1957: 280).

In addition to the predominance of negative attitudes in the usage guides analysed, two other aspects of the treatment of literally are worth addressing. The first is that the entries sometimes contain observations about the use of literally which are in line with descriptive accounts, even if the advice offered in the entries may be prescriptive. Observations that literally is 'acceptable only when it serves to show that an expression usually used metaphorically is to be taken at its word' (Bryson, 1984: 93) or that it 'is used more legitimately to emphasize the reality of facts or events that could be mistaken as figurative' (Sutcliffe, 1994: 79) illustrate that in some cases usage guides may contain descriptively relevant information about language use (in the context of historicalsociolinguistic studies this argument has been made before; see e.g. Poplack \& Dion, 2009; Tieken-Boon van Ostade, 2011; Anderwald, 2012). The second aspect is that there seems to 


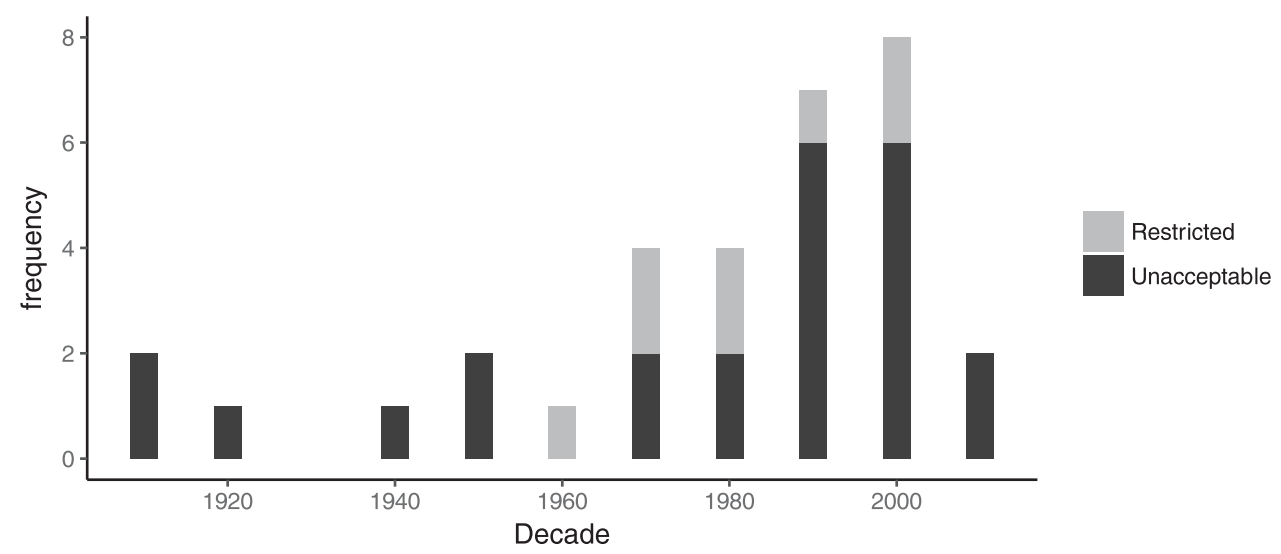

Figure 2. Treatment of literally in the usage guide entries per decade

be a lack of understanding of the function of literally, especially in DUAL USE contexts. Usage guide writers insist that literally is only acceptable in its primary, literal use and criticise intensifying uses of literally. However, in actual usage, the intensifying function of literally is combined with its literal meaning.

\section{Literally in the corpus data}

Turning to the results from the disambiguation of the occurrences of literally in the sample, Figure 3 shows that the most common use is the DUAL USE, followed by the BASIC USE, with the NONLITERAL USE being substantially the least frequent. This situation, moreover, does not appear to have changed drastically over the last two centuries. Although the proportion of DUAL USE seems to be somewhat larger in COCA than in COHA, at the expense of the BASIC USE, the difference is still small. It is difficult to know whether this difference is indicative of the rate of change in the distribution of the different uses of literally, or whether it is merely the result of the difference in the makeup of the corpora. ${ }^{3}$

All this supports Claridge's (2011: 109) observation that hyperbolic literally is not common in the corpus data, but goes against McCarthy \& Carter's (2004) finding that $91 \%$ of the instances of literally are hyperbolic. On the whole, the data may indicate that literally is undergoing a very slow process of semantic change. The very small number of the NONLITERAL examples shows that the lexeme has not yet been entirely stripped of its propositional meaning. The combination of high-frequency DUAL USE instances and the perception that these uses can be neatly distinguished from the intensifying ones may explain the negative treatment of literally in the usage guides, and the exaggerated perception of the frequency of the instances exhibiting NONLITERAL USE.

The analysis has also revealed that the interpretation of certain instances may be pragmatically conditioned, and that such cases are therefore ambiguous. In the instances of EXTREME USE, for example, the expression modified by literally may not straightforwardly denote an extreme or doubtful case, though the speaker may have intended it as such, and the very use of literally thus signals a potentially extreme reading. This creates a problem of circularity in determining extreme cases, because the use of literally is itself often a clue that the speaker aims to signal that something is surprising, doubtful or incredible. This may be one reason for the strikingly different findings for the use of literally with hyperbolic expressions reported by McCarthy \& Carter (2004) and Claridge (2011). These problems, however, do not affect the results presented here, because almost all ambiguous instances concern those which I consider to be representative of a single category, i.e. DUAL USE, in the present analysis. A more detailed discussion of this issue is beyond the scope of this paper (but see Kostadinova, forthcoming; Kostadinova, in preparation).

\section{Attitudes to literally}

As mentioned in Section 3.3, attitudes to literally were elicited by asking participants what they thought about the word. Elsewhere (Kostadinova, 2018), I focus on the different attitudes that the participants associated with the use of literally. Here, I will be concerned specifically with whether or not 

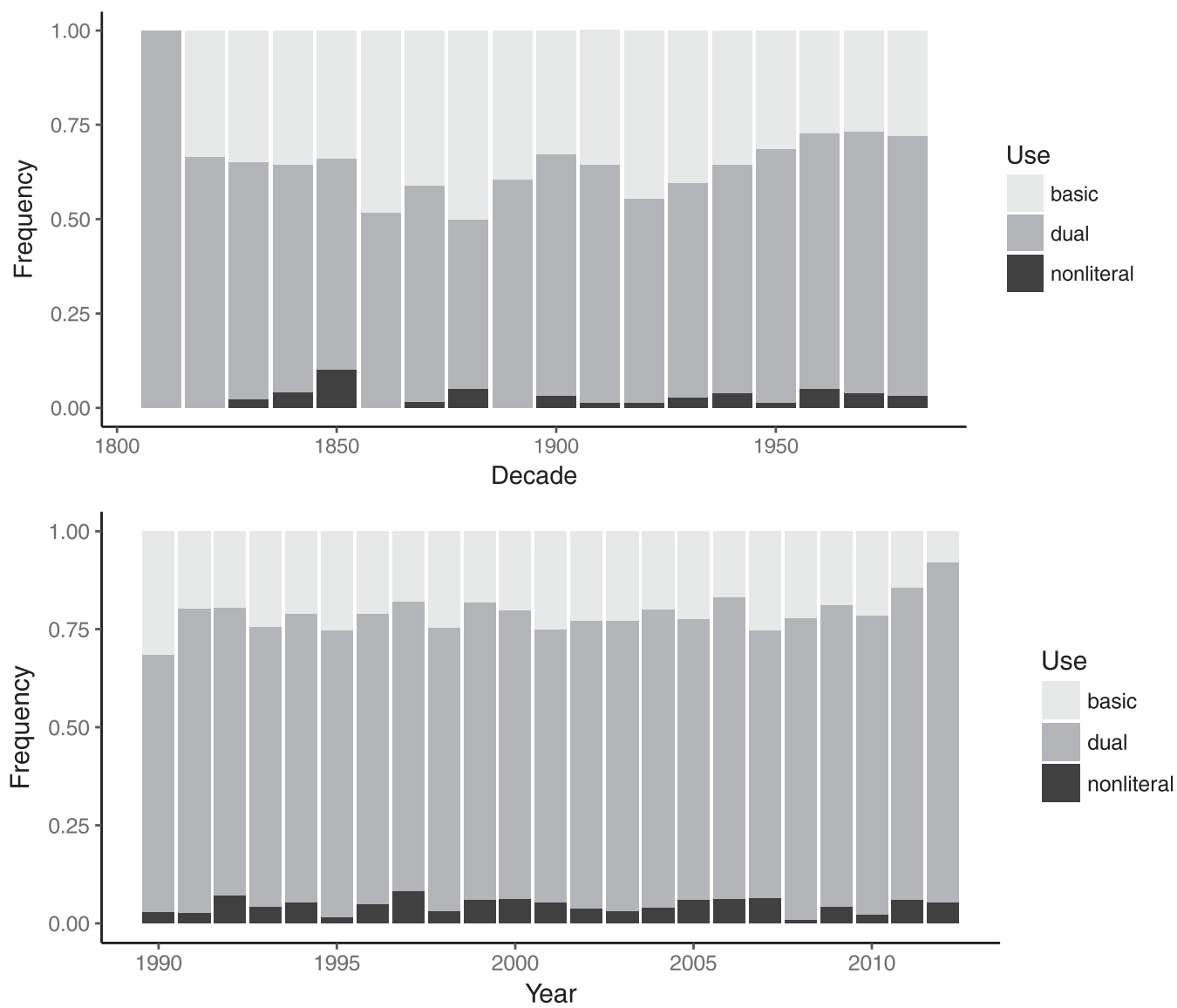

Figure 3. Distribution of the different uses of literally across time; the top figure is based on COHA, the bottom on COCA

the participants accept these newer uses of literally. It seems that, roughly speaking, the comments reflect the prescriptive-descriptive dichotomy. Some of the participants would not accept the word and the variation in its use, usually supporting this view by drawing on arguments evocative of the doctrine of correctness (Finegan, 1980: 10).

10. That word is awful. I try not to use it. People don't use it correctly. ( $\mathrm{T}, \mathrm{f}, 35)$

11. Language does evolve, and that is the eternal truth. If it changes for a reason other than dumbing down the language, I'm fine with that. But if it's literally just, 'oh, everyone uses it and everyone uses it incorrectly', it shouldn't be. I don't think Oxford should have added the second definition of literally to include figurative use of the word [ ... ] It's an incorrect use. (J, m, 19)

These comments show that some speakers express attitudes that are very much in line with prescriptive notions of correctness as being superior to actual language use. In other words, usage should satisfy the established standard of correctness. In the case in (11), the speaker even went so far as to claim that linguistic authorities, such as dictionaries ('Oxford' referring most likely to the Oxford English Dictionary), may fail to uphold the standards of correct usage.

On the other hand, there were also participants who, as shown in (12) and (13), either expressed no overt criticism of the use if literally or explicitly argued that the word is acceptable, based on their own observations of how people around them use it, or how they themselves do.

12. I literally do that all the time. I say literally when it's never it's never literal. It's like you want someone to believe you so much that like you wanna explain how you feel so you like use hyperbole. (A, f, 19) 
13. You know, I don't use [literally] myself very much and I think people use literally so much that I'm probably deaf to it [...] But, everyone does it now so I think that may be one that's getting more accepted and more normalised. ( $\mathrm{R}, \mathrm{f}, 32)$

Finally, one of the speakers who recognised literally as part of their own language use offered a more detailed account of why he saw literally as acceptable.

14. Sometimes I think the use of the word literally is just funny. I have done it before. A lot of us have. 'I literally wanted to kill myself!' The majority of people that I know, especially those I interact with, they use literally; they use it a lot. It's almost funny when they use it and it shows more breadth of languages because literally is, I mean, to know what literally means - it's actually a word that I don't think a lot of the general population, especially people who do not have interesting grammar, would actually know what it means. (J, m, 26)

In relation to this final comment, it is worth noting that Israel (2002: 424) makes a similar observation, noting that 'people use the word in this way precisely because they do understand the notion of literal meaning, and they associate it, naturally enough, with plain speaking and honest expression'. This comment may be indicative of the development of a certain type of prestige associated with the intensifying and hyperbolic use of literally among younger speakers. While I would tend to describe this as covert prestige (cf. Trudgill, 1972), as it is associated with a nonstandard form, this is still a tentative observation and more data is needed to ascertain the existence of such prestige, and the extent to which speakers express it overtly in a way exemplified in (14). The development of such prestige, however, coupled with the process of language change itself, may turn out to be critical in the eventual acceptance of the extended uses of literally.

\section{Conclusion}

This paper has explored the relationship between usage guides and actual language use, crucially focusing on insights into speakers' attitudes in order to arrive at an understanding of how presentday prescriptivism relates to processes of language change. The analysis of precept data showed that the majority of usage guides take a conservative approach to the variation in the use literally, frequently expressing strong negative attitudes towards the word. The increased frequency of use of literally in what I have called a DUAL USE is predominantly perceived as a mistake, a misuse or an overuse, while its frequent use is associated with carelessness and ignorance of the 'true' meaning of the word.

The corpus analysis, however, showed that the majority of those uses are not the 'absurd' or 'illogical' uses which usage guides disparage; they are, rather, uses in which literally is used to signal the necessity for a literal reading of an otherwise idiomatic, figurative or hyperbolic expression. These uses of literally are inextricably linked to a rhetorical dimension of providing emphasis, and consequently the word simultaneously functions as an intensifier. Usage guides thus fail to provide an appropriate account of the use of literally, by insisting that intensifying uses of literally are incorrect and unacceptable, while accepting only those uses in which literally forces a literal reading of idiomatic or figurative expressions. The analysis of the actual usage of literally reveals that these two uses, treated as separate in the usage guides, are in fact ineluctably part of the same use of literally. The predominance of this use, as opposed to BASIC USE and NONLITERAL USE, may explain the perception that literally 'is overused both as a disclaimer and an enhancer' (Sutcliffe, 1994: 79). With respect to the nature and direction of influence, the process of change that literally is undergoing does not seem to be affected in any way by the prescriptive constraints against its use. It seems rather that usage guides are simply reacting to this ongoing change.

Finally, the attitude data obtained through the interviews suggest that while many of the informants may be aware of the perceived incorrectness of literally in uses strongly characterised by rhetorical emphasis, they tend to accept the use on the basis of what they perceive to be common practice. Younger respondents readily admitted to using literally, some of them explaining that the newer uses of literally are part of how they speak, and how they use the word, despite their awareness of its 'technical' incorrectness. This, I believe, potentially indicates the development of possibly covert prestige associated with the use of literally. This conclusion suggests that what ultimately may influence processes of language change is not top-down prescriptive attitudes institutionalised through usage guides, but wider sociolinguistic processes that are at the core of speakers' everyday linguistic practice and experience. 


\section{Notes}

1 All examples of literally in this paper are taken from the corpus sample analysed. See Section 3 for information on the corpora consulted. For further examples of the uses of literally, see Powell (1992).

2 The information given in brackets is: year of the source text in the corpus, the corpus section and the corpus from which the example was taken.

3 The issue of statistical significance of these trends will be addressed in Kostadinova (in preparation).

\section{References}

Albakry, M. 2007. 'Usage prescriptive rules in newspaper language.' Southern Journal of Linguistics, 30(2), 28-56.

Anderwald, L. 2012. 'Clumsy, awkward or having a peculiar propriety? Prescriptive judgements and language change in the $19^{\text {th }}$ century.' Language Sciences, 34(1), 28-53.

Auer, A. \& González-Díaz, V. 2005. 'Eighteenth-century prescriptivism in English: A re-evaluation of its effects on actual language usage.' Multilingua, 24(4), 317-41.

Biber, D., Johansson, S., Leech, G., Conrad, S. \& Finegan, E. 1999. Longman Grammar of Spoken and Written English. Harlow: Longman.

Bierce, A. 1909. Write It Right: A Little Blacklist of Literary Faults. New York: Walter Neale.

Bryson, B. 1984. The Penguin Dictionary of Troublesome Words. London: Guild Publishing.

Calhoun, K. 2015. "It is the worst of our time": Youth language, language attitudes, and arguments about literally.' Proceedings of the $23^{\text {rd }}$ Annual Symposium about Language and Society - Austin. Texas Linguistics Forum, 58, 1-10.

Claridge, C. 2011. Hyperbole in English: A Corpus-Based Study of Exaggeration. Cambridge: Cambridge University Press.

Clark, R. P. 2010. The Glamour of Grammar. New York: Little, Brown and Company.

Connors, R. J. 1983. 'Handbooks: History of a genre.' Rhetoric Society Quarterly, 13, 87-98.

Copperud, R. H. 1980. American Usage and Style: The Consensus. New York: Van Nostrand Reinhold.

Creswell, T. 1975. Usage in Dictionaries and Dictionaries of Usage. Alabama: American Dialect Society.

Davies, M. 2008-. The Corpus of Contemporary American English (COCA): 520 million words, 1990-present. Online at $<\mathrm{http}: / /$ corpus.byu.edu/coca/ $>$ (Accessed October 31, 2017).

Davies, M. 2010-. The Corpus of Historical American English (COHA): 400 million words, 1810-2009. Online at $<$ http://corpus.byu.edu/coha/> (Accessed October 31, 2017).

Dekeyser, X. 1975. Number and Case Relations in $19^{\text {th }}$ Century British English: A Comparative Study of Grammar and Usage. Antwerp and Amsterdam: De Nederlandsche Boekhandel.

Ebbitt, W. R. \& Ebbitt, D. R. [1939] 1978. Writer's Guide and Index to English ( $6^{\text {th }}$ edn.) Glenview, IL: Scott, Foresman and Company.

Ebner, C. 2017. Proper English Usage: A Sociolinguistic Investigation of Attitudes towards Usage Problems in British English. Utrecht: LOT.
Evans, B. \& Evans, C. 1957. A Dictionary of Contemporary American Usage. New York: Random House.

Finegan, E. 1980. Attitudes Toward English Usage: A History of a War of Words. New York: Teachers College Press.

Gilman, E. W. (ed.) 1989. Webster's Dictionary of English Usage. Springfield, MA: Merriam-Webster Inc. Publishers.

Goatly, A. 1997. The Language of Metaphors. London and New York: Routledge.

Huddleston, R. \& Pullum, G. 2002. The Cambridge Grammar of the English Language. Cambridge: Cambridge University Press.

Israel, M. 2002. 'Literally speaking.' Journal of Pragmatics, 34(4), 423-32.

Johnson, E. D. [1982] 1991. The Handbook of Good English: Revised and Updated. (Revised edn.). New York and Oxford: Facts On File.

Kostadinova, V. 2018. 'Usage problems in American English.' In I. Tieken-Boon van Ostade (ed.), English Usage Guides: History, Advice, Attitudes. Oxford: Oxford University Press, pp.155-75.

Kostadinova, V. Forthcoming. Language Prescriptivism: Attitudes to Usage and Actual Use in American English. $\mathrm{PhD}$ Dissertation, Leiden University.

Kostadinova, V. In preparation. 'Variation and change in the use of literally: A corpus-based study.' (Working title).

McCarthy, M. \& Carter, R. 2004. "“There's millions of them": Hyperbole in everyday conversation.' Journal of Pragmatics, 36(2), 149-84.

Nerlich, B. \& Chamizo Domínguez, P. 2003. 'The use of literally: Vice or virtue?' Annual Review of Cognitive Linguistics, 1(1), 193-206.

O’Conner, P. T. 1996 Woe is I (repr. 1998). New York: Riverhead Books.

OED: Oxford English Dictionary. Online at <www.oed. com> (Accessed October 31, 2017).

Peters, P. 2004. The Cambridge Guide to English Usage. Cambridge: Cambridge University Press.

Peters, P. 2014. 'Usage guides and usage trends in Australian and British English.' Australian Journal of Linguistics, 34(1), 581-98.

Peters, P. \& Young, W. 1997. 'English grammar and the lexicography of usage.' Journal of English Linguistics, 25(4), 315-31.

Pinker, S. 2014. The Sense of Style. London and New York: Allan Lane.

Poplack, S. \& Dion, N. 2009. 'Prescription vs. praxis: The evolution of future temporal reference in French.' Language, 85(3), 357-87.

Powell, M. J. 1992. 'Folk theories of meaning and principles of conventionality: Encoding literal attitude via stance adverb.' In A. Lehrer \& E. F. Kitay (eds.), Frames, Fields, and Contrasts: New Essays in Semantic and Lexical Organization. New York and London: Routledge, pp. 333-53

Quirk, R., Greenbaum, S., Leech, G. \& Svartvik, J. 1985. A Comprehensive Grammar of the English Language. Harlow: Longman.

Stilman, A. 1997. Grammatically Correct. Cincinnati, OH: Writer's Digest Books.

Straaijer, R. 2014. Hyper Usage Guide of English Database. Online at $<$ http:/huge.ullet.net $>$ (Accessed October 31, 2017). 
Sutcliffe, A. J. 1994. The New York Public Library Writer's Guide to Style and Usage. New York: Harper Collins Publishers.

Tieken-Boon van Ostade, I. 2011. The Bishop's Grammar: Robert Lowth and the Rise of Prescriptivism. Oxford: Oxford University Press.

Tieken-Boon van Ostade, I. 2015. 'Five Hundred Mistakes Corrected: An early American usage guide.' In
M. Dossena (ed.), Transatlantic Perspectives on Late Modern English. Amsterdam and Philadelphia: John Benjamins, pp. 55-72.

Trudgill, P. 1972. 'Sex, covert prestige and linguistic change in the urban British English of Norwich.' Language in Society, 1(2), 179-95. 